\title{
SELF REGULATION WITH SENSORY PLAY FOR CHILDREN
}

\author{
Melani Aprianti \\ Universitas Mercu Buana Jakarta, Indonesia.
}

\begin{abstract}
Self-regulation in children 5-6 years really needs to be improved because at this age children often force the will (desire) by showing the ability to choose, do and decide something on their own. If the child already knows the rules, the child will feel secure, because the child knows which actions are allowed and which are not allowed. If the rules are embedded, the child will try to avoid the actions that are prohibited and tend to do things that are recommended. The purpose of this activity is to provide psychologists to help provide sensory games for children in PPKS Cempaka to provide stimulus to early childhood learning and self-regulation. Activities are given by PACE (Positive, Active, Clear, and Energetic method) or Positive, Active, Responsive, and Energetic through Brain gym activities.
\end{abstract}

Keywords : Emotion Regulation, Children, Learning

\section{Introduction}

Self-regulation in children 5-6 years really needs to be improved because at this age children often force their will (desire) by showing the ability to choose, do and decide something on their own. If the child already knows the rules, the child will feel secure, because the child knows which actions are allowed and which are not allowed. In addition, If the rules are embedded, the child will try to avoid the actions that are prohibited and tend to do things that are recommended. Early childhood who is able to control their emotions and behavior or action and is able to socialize well with its environment (Wahyuningtyas, 2015 ). Self-regulation is the ability to control emotions and behavior, as well as to control joy and to build positive social relationships with others (Morisson, 2012).

Related with that, so it is necessary to develop a method of self-regulation in children, one of them is a sensory game or sensory play. Sensory play comes from the words sense and play. The word sense or more commonly referred to as the senses, are the 5 human senses consisting of: vision (eyes), smell (nose), hearing (ear), touch (skin) and taste tongue), and movement ( proprioceptive: muscles and joints) and balance (vestibular: inner ear). The word play means game. Sensory play is a game that encourages children to use one or more senses, for example, chasing light, guessing sounds, playing to smell a variety of odors, jumping along lines, playing sand and water, etc.

Children develop not only because of genetic factors, but also because of environmental stimuli. When an environmental stimulus occurs, and enters the brain. Then, it is processed in such a way by the central nerve system that will produce a sensation and that sensation encourages the child's senses to move in responding to the stimulus. The more stimulus given, the more children get experience. Every stimulus given will produce a different response . The task of parents and educators is to facilitate children to get those experiences so that the data bank in the child's brain is more and more diverse. The purpose of sensory play is to set children at the 'just right' level so that children remain calm when responding to a stimulus. Every parent always wants their children to be smart, so they can go through periods of learning smoothly. Many attempts are made by parents to realize that their will or desire , such as by adding children's learning hours, and choosing the best school according to parents. Howevert, sometimes the results are also not optimal. Children are still slow in learning, do not put a lot effort. Additionally, they are undisciplined in carrying out their daily activities, and many more problems are encountered in children's education.

William and Schellenberger show that a child cannot necessarily think comprehensively without going through certain stages related to their age development .Nerve maturity is needed will gradually in preparing the child's brain structure so that it has perfect executive function.

Sensory system is the first part that must be generated by providing stimulation in order to enter the second stage which is responsible for the development of motor sensory. The third stage is the development of perceptual motor. Additionally, the fourth stage is cognitive / intellect. If every stage is given the right stimulation, then the target of a child having a high level of thinking will be realized. However, due to the instant desire of most adults, often these stages are missed, in which stimulation is given randomly / irregularly without proper understanding, resulting many parts that should be prepared to support the executive function of the brain become unprepared. In general, this can be seen when a child is less able to think critically strategically, less able to have empathy, and many more. Thus, the kid is less able to regulate himself. 


\section{Identification and Problem Formulation}

Based on the analysis of the above situation, it is known that sensory game is needed to prepare the child to learn and regulate themselves so that the faculty of Psychology UMB initiate in dedicating to provide sensory games to stimulate early children ages to learn and regulate themselves.

\section{Method}

The methods are: Provide a re-explanation about the importance of sensory play on children's self- regulation, provide an explanation of the play activities that can be carried out to build relationships according to the child's age, give sensory games to children. start the game. The aims of the program evaluation are to see whether there are positive or negative influences after the game. The results of this evaluation are intended as a reference in developing the next service program.

Picture 1. Introduction

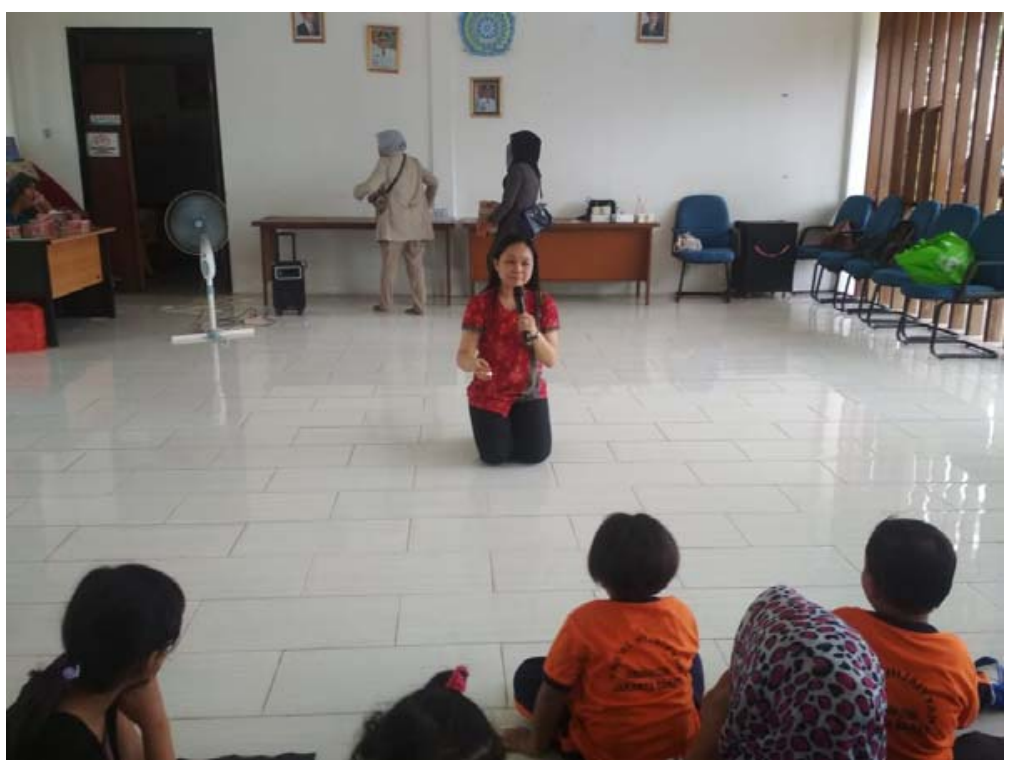

Picture 2. Cross movement

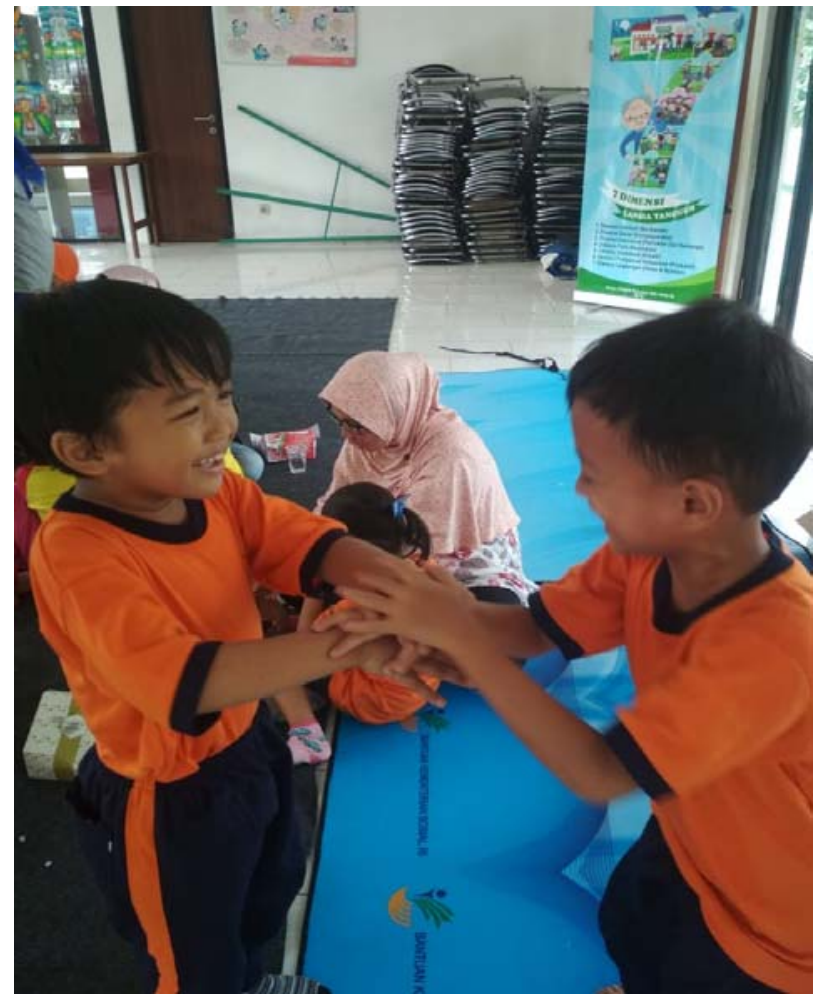

Picture 3. Brain Gym 


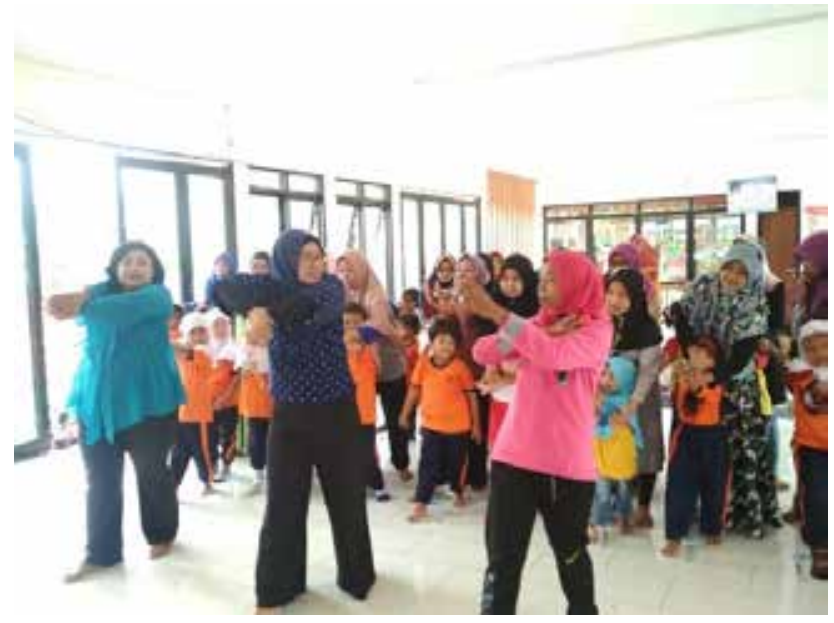

Picture 4. Sensory Play

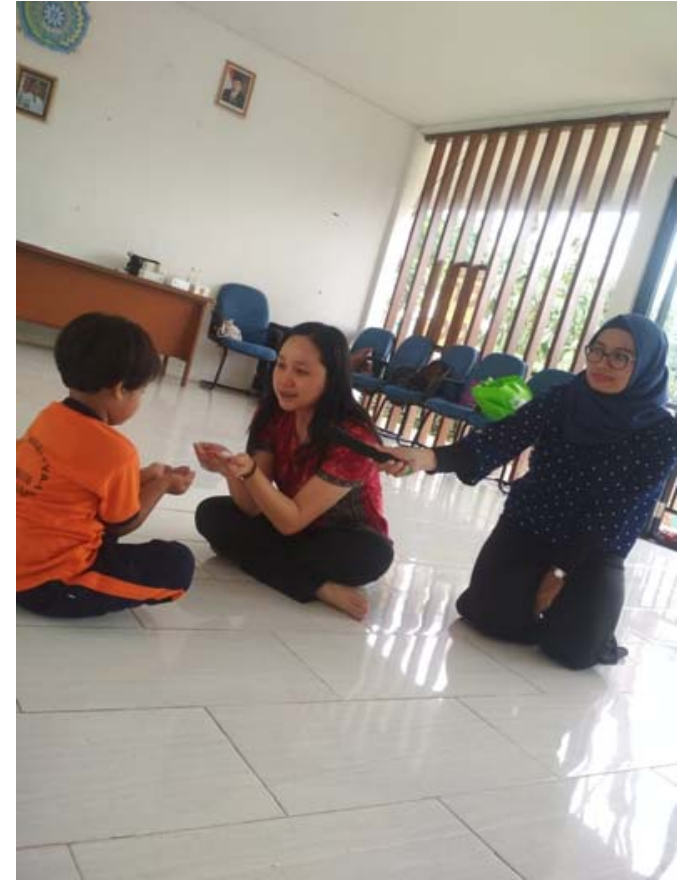

Picture 5. With Children and Parents

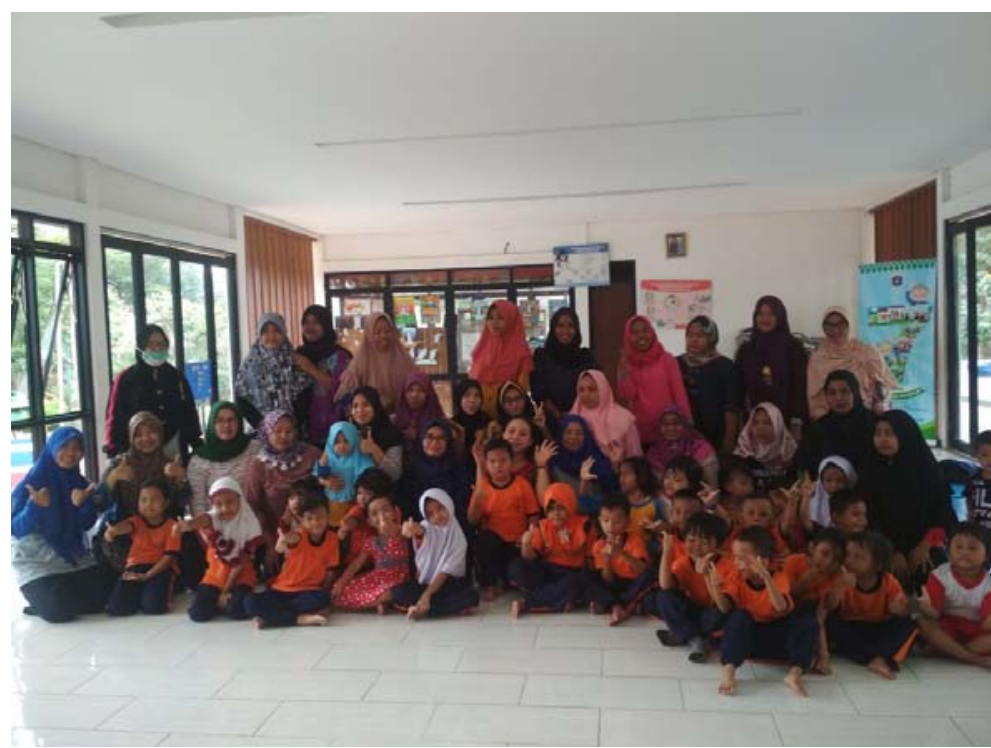




\section{Result and Activities}

This activity took place at PPKS Cempaka. The number of participants in this activity is 39 people. This event was held in the Cempaka PPKS Hall. The participants of this activity are children aged 5-6 years and parents who accompany them in order to understand the concept of sensory games for children.

This activity started at 10:00 and ended at 11:30. This activity received a lot attention and enthusiasm from the participants. Because counseling is given with the concept of play and participants find it very useful in gaining knowledge about sensory games and their effects on children's self regulation.

Activities are given using the PACE (Positive, Active, Clear, and Energetic) method or Positive, Active, Responsive, and Energetic through Brain Gym activities and consist of 4 simple movements, namely:

1. Drinking water

The purpose of drinking water is:

a) Improve electrical and chemical communication between the brain and nerve system because our body consists of approximately $70 \%$ water, and water. The water itself is needed as a medium to electrical energy. An electrical and chemical activity in the brain and central nerve system depend on the smoothness flowing between the brain and the sensory

b) Support the ability to store information and readiness to use it

c) Improve the ability to concentrate

d) Reduce stress

e) Support mental and body coordination.

f) Improve all skills needed to learn.

2. Brain Button

Participants were asked to make movements by touching the navel, massaging the left and right sides of the middle bone, right in two grooves The hand in the navel is intended to balance the impulses associated with the inner ear and affects the ability to learn in children

3. Cross movement

Participants are asked to touch their right knee with their left hand /left elbow and right hand in relaxed position toward the side and vice versa. The child's right brain controls the left part of body and vice versa. The crawling movement can support and it leads to left and right coordination.

\section{Hooks Up}

There are two parts in this movement, namely part 1 and part 2.

Part 1 is that participants are asked to sit, lie down or stand crossing their left leg on their right foot and left hand on their right hand with their thumbs down toward fingers holding both hands together. Then pull both hands toward the navel and front of the chest. Participants are asked to close their eyes and take a deep breath while relaxing. When breathing in through the nose, the tongue is stuck to the palate of the mouth, and when exhaling, the tongue is released again.

Part 2, after part 1 is finished, the feet are placed side by side, the tips of the fingers of both hands are gently connected while continuing deep breathing.

\section{Discussion}

Participants initially did not know how to stimulate children in self-regulation. especially, at $\mathrm{t}$ school. It can also be done to increase interaction between the children and parents. This stimulus movement is easier to do for children who like to move and if it is done effectively can increase concentration and provide stimulus for children in self-regulation.

\section{Conclusion}

Through this counseling center activity in the Cempaka PPKS society, the community is helped in getting education about preventive and curative measures related to psychological problems, education, child development and other family problems. Thus, the mental health environment of PPKS can be further improved by maximizing the delivering the material in developing children through training activities.

To improve the quality of community service programs. There are some following suggestions that can be done :

1. Further community service programs in the form of providing sensory games can be done more frequently on a regular basic.

2. Community service programs in the form of providing sensory games can be carried out in other areas. So that other community can feel the impact more widely 


\section{Bibliography}

Wahyuningtyas, Dessy Putri. (2015). "Mengembangkan Regulasi Diri Melalui Pemberian Penghargaan”. Jurnal Pendidikan Usia Dini Volume 9 Edisi 1, April 2015.

Morrison, George S. (2012). Dasar-Dasar Pendidikan Anak Usia Dini (PAUD) terjemahan Suci Romadhona \& Apri Widiastuti. Jakarta: Indeks, 2012. 